\title{
Editorial: Looking Beyond Greenness: Transdisciplinary Approaches to Urban Green Spaces, Uses and Functions
}

\author{
Diogo Guedes Vidal ${ }^{1 *}$, Ricardo Cunha Dias ${ }^{2}$, Paulo Castro Seixas ${ }^{2}$, Nelson Barros ${ }^{1}$ and \\ Rui Leandro Maia ${ }^{3}$ \\ 13 BER - Energy, Environment and Environmental and Public Health Research Laboratory, UFP Energy, Environment and \\ Health Research Unit (FP-ENAS), Faculty of Science and Technology, University Fernando Pessoa, Porto, Portugal, ${ }^{2}$ Centre \\ for Public Administration and Public Policies, Institute of Social and Political Sciences, University of Lisboa, Lisboa, Portugal, \\ ${ }^{3} 3 E R L$ - Energy, Environment and Environmental and Public Health Research Laboratory, UFP Energy, Environment and \\ Health Research Unit (FP-ENAS), University Fernando Pessoa, Porto, Portugal
}

Keywords: urban green spaces, urban greening uses and functions, ecological and social systems, ecosystem services framework, transdisciplinary understanding of urban green spaces

\section{Editorial on the Research Topic}

Looking Beyond Greenness: Transdisciplinary Approaches to Urban Green Spaces, Uses and Functions

\section{OPEN ACCESS}

Edited and reviewed by: Stephan Pauleit,

Technical University of Munich, Germany

*Correspondence:

Diogo Guedes Vidal

diogoguedesvidal@hotmail.com

Specialty section: This article was submitted to

Urban Greening,

a section of the journal

Frontiers in Sustainable Cities

Received: 29 November 2021 Accepted: 08 December 2021 Published: 24 December 2021

Citation:

Vidal DG, Dias RC, Seixas $P C$, Barros N and Maia RL (2021) Editorial:

Looking Beyond Greenness: Transdisciplinary Approaches to Urban Green Spaces, Uses and

Functions.

Front. Sustain. Cities 3:824472. doi: $10.3389 /$ frsc. 2021.824472
Urban Green Spaces (UGS) are a central component of urban sustainability and resilience. The multiple benefits that result from UGS are well-documented and go far beyond the environmental dimension: promoting well-being and social cohesion, enhancing physical activity, and providing opportunities to relax and restore within the dense urban environment (Lee et al., 2015; Braubach et al., 2017; Jennings and Bamkole, 2019; Vidal et al., 2021b). Despite these ecosystem services, some disservices have been pointed out in the literature. These disservices are related to the urban vegetation, where the "choice for trees" must consider that some species emit biogenic volatile organic compounds (BVOC). Such BVOC could lead to the development of ozone (O3) and the degradation of air quality (Graça et al., 2018). Other disservices have been identified: the displacement of native species and, synchronically, the introduction of invasive species in gardens and parks; lower possibilities to use sunlight because of spacious shade; indirect costs caused by land-use restrictions; direct costs caused by planting, maintaining, and removing planted areas; negative health effects related to the pollen released by some plant species (von Döhren and Haase, 2015; Lyytimäki, 2017). Nevertheless, adaptive design and the management of UGS could contribute to minimizing disservices of the ecosystem (Teixeira and Fernandes, 2016, 2017).

Considering this closer, UGS are complex socioecological systems as they combine both the social and the ecological sphere. Current literature contributed to further elaborate on UGS and their ecosystem services provision (Haines-Young and Potschin, 2018). In spite of those efforts made, ongoing debates still lack a deep meaning about the functions and uses of UGS, which is the most challenging dimension yet to be measured (Fish et al., 2016).

Functions and uses of UGS urge for a strong transdisciplinary approach, what could be the reason for the current absence of deeper discussions about this matter. Planning UGS in an era of unpredictability and uncertainty requires a well-built transdisciplinary view to properly address human-nature relations and to integrate scientific knowledge into the decision-making process (Vidal et al., 2021c). 
Such a lack of knowledge results in the complex phenomena of environmental and social inequalities which are gaining expression specifically within urban areas. Even though it must be acknowledged that other existing contributions within UGS research, embedded within different disciplinary fields, are of great relevance (such as multidimensional research approaches), transdisciplinary perspectives about this matter still lack on subsistence and visibility.

So far, previous research has focused on the production of knowledge to improve the quality of the urban environment and to promote the well-being of the population. Notwithstanding, structural inefficiencies and inequalities constantly reproduced in the dense urban environment have been neglected thus far (Jennings et al., 2021). This is closely linked with the unfair distribution of UGS in urban spaces, revealing that disadvantaged communities have lesser physical and symbolic access to qualitative UGS (Dai, 2011; Hoffimann et al., 2017; Vidal et al., 2021a). The phenomenon of "green gentrification" (Curran and Hamilton, 2018) is a further problem which urges for the consideration of environmental injustice enforced by non-equity-oriented policies for urban greening. This, for instance, becomes evident in situations where wealthier migrants experience more benefits compared to those who are socially disadvantaged.

Given such shortfalls, the main challenge is to enforce a collective effort to look beyond the greenness, previously addressed by articles integrated within this special issue.

Considering the contribution provided by Noël et al., the authors sought to address how social barriers undermine the availability and accessibility of public UGS in the Brussels Capital Region through the application of 51 individual face-to-face indepth interviews. Three main barriers emerged from the field, such as (i) the fear to use the space due to the lack of social controls or presence of unpleasant elements, (ii) the lack of sense of belonging resulting from the dominance of a specific social group, (iii) and the fact that the public UGS may not fulfill users social needs, suggesting that their social context and needs should be considered in the future interventions in these spaces.

Furthermore, $\mathrm{Haq}$ et al. provide a comprehensive understanding of convergences and divergences in UGS as socially perceived on a planetary scale. The findings of their review encourage the use of integrated multidisciplinary approaches and the combination and application of innovative tools to identify users' perceptions. Moreover, it concludes that as far as residents' perceptions of and attitudes toward UGS are considered within urban planning and design processes, benefits provided by these spaces may be highly increased.

Another study strongly engages with the experiences and perceptions of urban park visitors in Lisbon/Portugal (Alameda and Estrela) (Viebrantz and Fernandes-Jesus).

Through a questionnaire applied to 188 users of UGS, the authors of this research evaluated the physical and natural characteristics of UGS, as well as their accessibility, the surrounding areas, motives for use and importance, quality, and quantity. Visitors are aware that UGS may play a vital role in the distribution of relaxing opportunities, as well as recreation, socialization, and physical activities. Estrela park, for instance, is less often visited than Alameda. Nevertheless, users tend to stay longer in the former one due to its pleasant landscape and restful natural environment. In a general overview, the research participants highlighted the need for more parks in the urban space of Lisbon, as well as better maintenance and, most importantly, a more equal distribution within the city.

Finally, a research conducted in England by McClymont and Sinnett aims to contribute to the role of cemeteries within a multifunctional network of a green infrastructure, concerning their accessibility through a two-step analysis. The first one considers the national availability of cemeteries as UGS of proximity, especially in high density urban environments, representing around $4 \%$ of accessible greenspaces. Secondly, using the city of Bristol as a case study, the authors surveyed 11 cemeteries, through which they discovered their potential to strongly engage with ecosystem services through acknowledging the need to sustain cultural sensitive spaces for burial and remembrance. Moreover, the study reveals an intense dialogue between the actual actors engaged in the maintenance and provision of cemeteries.

The outstanding contribution of the articles presented in this special issue, covering a wide range of UGS dimensions, gives solid support to the challenge initially proposed: to look beyond the greenness. Finally, we argue that in order to enforce urban sustainability and resilience and, most importantly, to maintain the well-being of city dwellers, "UGS planning and design" needs to strongly consider both ecological and social perspectives.

\section{AUTHOR CONTRIBUTIONS}

DV wrote the first draft of the manuscript. RD, PS, NB, and RM have contributed to manuscript's final version and read. All authors contributed to the article and approved the submitted version.

\section{FUNDING}

DV is financed by the Fundação para a Ciência e a Tecnologia, I.P., through the SFRH/BD/143238/2019 grant, supported by the European Social Fund, MCTES National Funds, and the Human Capital Operational Program.

\section{ACKNOWLEDGMENTS}

DV, NB, and RM would like to thank to UFP Energy, Environment and Health Research Unit (FP-ENAS), an R\&D unit (4546) recognized by the Fundação para a Ciência e a Tecnologia, I.P. RD would like to thank to Fundação para a Ciência e a Tecnologia (FCT, I.P.) through the Doctoral Grant SFRH/BD/135804/2018. 


\section{REFERENCES}

Braubach, M., Egorov, A., Mudu, P., Wolf, T., Ward Thompson, C., and Martuzzi, M. (2017). "Effects of urban green space on environmental health, equity and resilience," in Nature-Based Solutions to Climate Change Adaptation in Urban Areas, eds. N. Kabisch, H. Korn, J. Stadler, and A. Bonn (Cham: Springer International Publishing) 187-205. doi: 10.1007/978-3-319-56091-5_11

Curran, W., and Hamilton, T. (2018). Just Green Enough: Urban Development and Environmental Gentrification. London: Routledge.

Dai, D. (2011). Racial/ethnic and socioeconomic disparities in urban green space accessibility: where to intervene? Landsc. Urban Plan. 102, 234-244. doi: 10.1016/j.landurbplan.2011.05.002

Fish, R., Church, A., and Winter, M. (2016). Conceptualising cultural ecosystem services: a novel framework for research and critical engagement. Ecosyst. Serv. 21, 208-217. doi: 10.1016/j.ecoser.2016.09.002

Graça, M., Alves, P., Gonçalves, J., Nowak, D. J., Hoehn, R., FarinhaMarques, P., et al. (2018). Assessing how green space types affect ecosystem services delivery in Porto, Portugal. Landsc. Urban Plan. 170, 195-208. doi: 10.1016/j.landurbplan.2017.10.007

Haines-Young, R., and Potschin, M. B. (2018). Common International Classification of Ecosystem Services (CICES) V5.1 and Guidance on the Application of the Revised Structure. Nottingham Available online at: www.cices.eu (accessed November 20, 2021).

Hoffimann, E., Barros, H., and Ribeiro, A. I. (2017). Socioeconomic inequalities in green space quality and accessibility - evidence from a Southern European city. Int. J. Environ. Res. Public Health. 14:916. doi: 10.3390/ijerph14080916

Jennings, V., and Bamkole, O. (2019). The relationship between social cohesion and urban green space: an avenue for health promotion. Int. J. Environ. Res. Public Health 16:452. doi: 10.3390/ijerph16030452

Jennings, V., Reid, C. E., and Fuller, C. H. (2021). Green infrastructure can limit but not solve air pollution injustice. Nat. Commun. 12:4681. doi: 10.1038/s41467-021-24892-1

Lee, A., Jordan, H., and Horsley, J. (2015). Value of urban green spaces in promoting healthy living and wellbeing: prospects for planning. Risk Manag Heal. Policy 8, 131-137. doi: 10.2147/RMHP.S61654

Lyytimäki, J. (2017). "Disservices of urban trees," in Routledge Handbook of Urban Forestry, eds F. Ferrini, C. C. K. van den Bosch, and A. Fini (London; New York, NY: Routledge) 164-176. doi: 10.4324/9781315627106.ch12

Teixeira, C. P., and Fernandes, C. O. (2016). "Adaptive planting design: vegetation as tool to solve (existing) problems," in ECLAS Conference 2016 - Bridging the Gap, eds. P. Bauer, M. Collender, M. Jakob, L. K. Bonnelame, P. Petschek,
D. Siegrist, and C. Tschumi (Rapperswil: HSR Hochschule für Technik), 501-504. Available online at: https://ilf.hsr.ch/fileadmin/user_upload/ilf.hsr. ch/4_Projekte/ECLAS/161025_Eclas/Proceedings 2016.pdf

Teixeira, C. P., and Fernandes, C. O. (2017). "Adaptive planting design: requalification of the garden of the nursing school of Porto," in Green Surge International Conference: Urban Green Infrastructure - Connecting People and Nature for Sustainable Cities (Malmõ).

Vidal, D. G., Fernandes, C. O., Viterbo, L. M. F., Vilaça, H., Barros, N., and Maia, R. L. (2021b). Usos e perceções sobre jardins e parques públicos urbanos: resultados preliminares de um inquérito na Cidade Do Porto (Portugal) [Uses and perceptions of urban public gardens and parks: preliminary results of a survey in the City of Porto (Portugal)]. Finisterra Rev. Port. Geogr. 56, 137-157. doi: 10.18055/FINIS19813

Vidal, D. G., Fernandes, C. O., Viterbo, L. M. F. V., Vilaça, H., Barros, N., and Maia, R. L. (2021a). Combining an evaluation grid application to assess ecosystem services of urban green spaces and a socioeconomic spatial analysis. Int. J. Sustain. Dev. World Ecol. 28, 291-302. doi: 10.1080/13504509.2020.1808108

Vidal, D. G., Salata, S., Vilaça, H., Barros, N., and Maia, R. L. (2021c). Envisioning the future in public urban green spaces planning and design. Lessons from Porto. Urban. Inf. 297, 52-57.

von Döhren, P., and Haase, D. (2015). Ecosystem disservices research: a review of the state of the art with a focus on cities. Ecol. Indic. 52, 490-497. doi: 10.1016/j.ecolind.2014.12.027

Conflict of Interest: The authors declare that the research was conducted in the absence of any commercial or financial relationships that could be construed as a potential conflict of interest.

Publisher's Note: All claims expressed in this article are solely those of the authors and do not necessarily represent those of their affiliated organizations, or those of the publisher, the editors and the reviewers. Any product that may be evaluated in this article, or claim that may be made by its manufacturer, is not guaranteed or endorsed by the publisher.

Copyright ( 2021 Vidal, Dias, Seixas, Barros and Maia. This is an open-access article distributed under the terms of the Creative Commons Attribution License (CC $B Y)$. The use, distribution or reproduction in other forums is permitted, provided the original author(s) and the copyright owner(s) are credited and that the original publication in this journal is cited, in accordance with accepted academic practice. No use, distribution or reproduction is permitted which does not comply with these terms. 